\title{
A comparative study of the photochemistry of biphenyl adsorbed on cellulose and silicalite
}

\author{
J. P. Da Silva ${ }^{1,2, \dagger}$ and L. F. Vieira Ferreira ${ }^{1}$ \\ ${ }^{1}$ Centro de Química-Física Molecular, Instituto Superior Técnico, 1049-001 Lisboa, Portugal \\ ${ }^{2}$ FCT, Universidade do Algarve, Campus de Gambelas, 8005-039 Faro, Portugal
}

\begin{abstract}
The photochemistry of biphenyl (BP) was studied on two model solid supports, silicalite and cellulose, using time resolved diffuse reflectance techniques and product degradation analysis. The results showed that the photochemical behaviour of BP depends on the solid support. Ground state absorption spectra indicated a near planar configuration in the ground state. BP triplet state was the only species detected on cellulose, while the radical cation $\left(\mathrm{BP}^{\bullet+}\right)$ was observed in silicalite. BP is relatively stable in both supports. Prolonged irradiations in cellulose lead to the formation of the three monohydroxybiphenyls, while in silicalite photooxidation products prevailed.
\end{abstract}

\section{INTRODUCTION}

The widespread release of polychlorinated biphenyls (PCBs) into the environment presents a serious problem due to their persistence and toxicity. Their potential impact in human health, particularly with regard to growth and development, is well known [1]. PCBs tend to bio accumulate through the food chains and are very resistant to degradation by chemical and biological agents in environmental conditions [2].

Ultraviolet radiation from sunlight remains as a possible route for their inactivation in natural conditions. Unfortunately most PCBs do not absorb strongly above $290 \mathrm{~nm}$ and their direct photolysis proceeds with very low quantum yields [3, 4]. Several sensitizers and other additives have been used to enhance the photolysis under sunlight irradiation [5-8]. The photocatalytic degradation and mineralization by $\mathrm{TiO}_{2}$ is one of the most important tools to achieve their destruction [8-10]. $\mathrm{TiO}_{2}$ significantly increases the decomposition rates and dechlorination is the main photoreaction process.

BP and some of its chlorinated derivatives have been subjected to detailed photophysical and photochemical studies on the surfaces of $\gamma$-alumina and silica-alumina [11], clays [12, 13] and zeolites [14, 15]. According to the diffuse reflectance absorption spectra obtained on activated surfaces, a shift and broadening of the spectral absorption bands take place and surface complexes and ionisation occurs [11, 12]. On activated surfaces both $\mathrm{BP}$ and its charge transfer complex absorb above $290 \mathrm{~nm}$, allowing the direct photoreaction of these compounds in natural conditions. At low loadings, photo irradiation results in the formation of $\mathrm{BP}^{\bullet+}$ and of trapped electrons, which can be observed by ground state and time resolve diffuse

†E-mail: jpsilva@ualg.pt reflectance absorption [11-15]. At high loadings the formation of the radical anion $\left(\mathrm{BP}^{0^{-}}\right)$was also reported [14]. The main reaction of $\mathrm{BP}^{\bullet+}$ on surfaces is hydrolysis. The radical $\mathrm{BPOH}^{*}$ is suggested as a key intermediate in the hydroxylation, although it was not directly observed [11, 12]. Analysis by HPLC of the irradiated samples showed that hydroxybiphenyls are the main degradation products $[11,12]$.

In order to start studying this group of pollutants we selected cellulose and silicalite as supports and BP as starting model compound. Cellulose has been used as solid powdered support to study the photophysics and photochemistry of several organic probes at the solid/gas interface [16-19]. Some properties of this support, namely the extremely reduced diffusion of oxygen, make it particularly attractive for room temperature luminescence studies. From the environmental point of view, the knowledge of the photochemical behaviour of these pollutants on cellulose is important to assess their photochemistry after deposition on vegetal surfaces in natural conditions, since this support is one of the main structural components of vegetal cells. It is well known that toxic compounds like PCBs, dioxins and dibenzofurans are formed during the paper bleaching process $[20,21]$. Therefore the photophysical and photochemical properties of these xenobiotics on cellulose can also be used in devising methods for their transformation in less toxic compounds.

In this paper we report transient absorption results of BP adsorbed on silicalite and microcrystalline cellulose. The main photodegradation products were analysed and the main degradation pathways are discussed.

\section{EXPERIMENTAL}

2.1. Materials. BP, 4-hydroxybiphenyl, 3-hydroxybiphenyl (Aldrich), 2-hydroxybiphenyl, cellulose (Fluka), benzaldehyde (Riedel-de Haën), silicalite (Union 
Carbide), methanol, acetonitrile and iso-octane (Merck Lichrosolv) were used without further treatment. Water was deionized and distilled.

2.2. Sample preparation. Samples containing 50, $100,250,500$ and $1000 \mu \mathrm{mol} \mathrm{g}^{-1}$ of BP in silicalite were prepared by adding a solution of the probe in isooctane (solvent that is not able to penetrate into silicalite channels) to the correspondent quantity of the adsorbent, as described in a previous work with silicalite [18]. Samples were continuously mixed with a magnetic stirrer until all the solvent was evaporated. In some cases the removal of the probe from the external surface of the support was done using iso-octane again (three aliquots, $5 \mathrm{~mL}$ each) followed by a final drying procedure. Finally the samples were dried under reduced pressure ( $\left.10^{-3} \mathrm{mbar}\right)$. Adsorption of BP onto dried microcrystalline cellulose was achieved by adding the support to an ethanol solution with the correspondent amount of BP and allowing it to equilibrate for 24 hours under stirring. The mixtures were then continuously stirred until all the solvent was evaporated. Final traces of the solvent were removed under reduced pressure $\left(\sim 10^{-3}\right.$ mbar $)$.

\subsection{Methods}

(a) Diffuse reflectance laser flash photolysis system and laser induced luminescence

Laser flash photolysis experiments were carried out with the fourth harmonic of a Nd:YAG laser $(266 \mathrm{~nm}$, $6 \mathrm{~ns}$ FWHM, 10-30 mJ/pulse) from B. M. Industries (Thomson-CSF), model Saga 12-10, in the diffuse reflectance mode. A schematic diagram of the system is presented in reference [22]. The light arising from the irradiation of the solid samples by the laser pulse is collected by a collimating beam probe coupled to optical fibers (fused silica) and detected by a gated intensified charge coupled device (ICCD, Oriel model Instaspec V) after passing via a compact fixed imaging spectrograph (Oriel, model FICS 77440). The system can be used either by capturing all light emitted by the sample or in time resolved mode, using a delay box (Stanford Research Systems, model D6335). The ICCD has high speed gating electronics (2.2 ns) and intensifier, and works in the $200-900 \mathrm{~nm}$ wavelength range. Time resolved absorption and emission spectra are available in the nanosecond to second time range.

Transient absorption data are reported as percentage of absorption (\% Abs.) defined as $100 \Delta J_{t} / J_{0}=$ $\left(1-J_{t} / J_{0}\right) 100$, where $J_{0}$ and $J_{t}$ are the diffuse reflected light before exposure to the laser pulse and at time $t$ after excitation, respectively. In all samples the initial transient absorption ( $\leq 20 \%$ ) increased proportionally with laser intensity, giving evidence for the validity of this treatment, rather than the Kubelka-Munk analysis $[23,24]$.
Ground state absorption spectra of the solid powdered samples were very difficult to obtain due to the strong fluorescence of the samples. The problem was solved by the use of the above described laser flash photolysis setup. Both blank and samples were illuminated with the xenon lamp and the diffuse reflected radiation was collected by the ICCD. The radiation reflected by the blank $\left(\mathrm{I}_{0}\right)$ and by the samples $\left(\mathrm{J}_{0}\right)$ allowed the calculation of the reflectance $R\left(\mathrm{~J}_{0} / \mathrm{I}_{0}\right)$, which was then used to obtain the remission function $F(R)$ using the Kubelka-Munk equation

$$
F(R)=\frac{(1-R)^{2}}{2 R}=\frac{K}{S}
$$

where $K$ and $S$ are the absorption and scattering coefficients, respectively. In this way, and with one of the analysing monochromators, the fluorescence from the BP samples is eliminated. The Kubelka-Munk equation applies to optically thick samples, i.e., those where any further increase in the thickness does not affect the experimentally determined reflectance. For an ideal diffuser, where the radiation has the same intensity in all directions, $K=2 \varepsilon C$, where $\varepsilon$ is the Naperian absorption coefficient and $C$ is the concentration. Since the support usually absorbs at the excitation wavelength, $F(R)_{\text {probe }}=F(R)-F(R)_{\text {support }}=\sum_{i} 2 \varepsilon_{i} C_{i} / S$. This equation predicts a linear relationship for the remission function of the probe as function of the concentration (for a constant scattering coefficient) when the probe is only in the form of monomer.

\section{(b) Irradiation, degradation kinetics and product analysis}

Photodegradation studies were conducted in a reactor previously used to study the photochemistry of pesticides [25-27], chlorophenols [28, 29] and other compounds [30, 31]. The samples were irradiated at $254 \mathrm{~nm}$ using a $16 \mathrm{~W}$ low-pressure mercury lamp (applied photophysics) without filters and refrigeration. The samples were placed on Petri dishes and irradiated at a distance of $2 \mathrm{~cm}$ from the lamp housing. The photodegradation products were extracted by washing the irradiated samples with acetonitrile. Photolysis was followed by HPLC using a Merck-Hitachi 655A-11 chromatograph equipped with detectors 655A-22 UV. A column LiChroCART 125 (RP-18, $5 \mu \mathrm{m}$ ) Merck was used and the runs were performed using mixtures water/acetonitrile as the eluent. The extracts were also analysed by GC-MS using a Hewlett Packard 5890 Series II gas chromatograph with a 5971 series mass selective detector (E.I. $70 \mathrm{eV}$ ). A CP-WAX 58CB capillary column with $25 \mathrm{~m}$ length and $0.25 \mathrm{~mm}$ I.D. (Chrompack) was used. The initial temperature $70{ }^{\circ} \mathrm{C}$ was maintained during $5 \mathrm{~min}$ and then a heating rate of $5^{\circ} \mathrm{C} / \mathrm{min}$ was used until a final temperature of $250^{\circ} \mathrm{C}$ was reached. Analyses were conducted on irradiated and control samples, which were 
kept in the dark during irradiation. Controls showed no sign of BP degradation.

\section{RESULTS AND DISCUSSION}

3.1. Ground state diffuse reflectance absorption spectra. The structure, spectral localization and width of the absorption spectra may supply very important information about the molecular geometry of BP. In solution its ground state prefers a non-planar configuration due to the steric interaction between the hydrogen atoms at the 2,2'- and 6,6'-positions [32]. Upon absorption, molecules with varying degrees of nonplanarity act as absorbers, and a structureless spectrum results from the overlapping of a multitude of spectra, each spectrum corresponds to molecules with a particular geometry. This spectral broadening has been observed for BP in solution and adsorbed on several surfaces [11, 12]. Figure 1 shows the ground state absorption of BP in cellulose and silicalite (obtained as described in the experimental section) and in methanol and iso-octane solutions.

A comparison between the spectra obtained in solution and at the solid/gas interface indicates a bathochromic shift $(\sim 30 \mathrm{~nm})$ for the latter case. This result, although dependent on the energy of the singlet state, suggests a near planar nuclear conformation of the ground state since as the nuclear conformation becomes more planar and linear, a smaller Stokes loss is observed. Similar bathochromic shifts were observed for BP adsorbed on laponite surfaces [12] while on $\gamma$ alumina and silica-alumina similar spectral localization to that found in solution was observed [11]. As expected and unlike that observed in active surfaces, no charge transfer complex is formed in both supports. However the adsorption induces a strong red shift in the absorption spectra leading to an overlap region with the solar spectrum at ground level, allowing for possible direct photodegradation of BP in natural conditions.

\subsection{Diffuse-reflectance laser flash photolysis and} time resolved luminescence. Figure 2 shows the transient absorption spectra of BP on cellulose and silicalite.

The former support presents a main transient absorption band, centered at $370 \mathrm{~nm}$. By comparison with the transient absorption spectra available in literature [14] this band was attributed to triplet-triplet absorption. Time resolved luminescence showed a strong emission in the ms time scale, centered at $470 \mathrm{~nm}$ (see Figure 3).

This is the phosphorescence emission of BP [12] and confirms the presence of its triplet state on cellulose.

In silicalite a long wavelength transient absorption band centered at $670 \mathrm{~nm}$ with a shoulder at $620 \mathrm{~nm}$ was also observed. By comparison with the results obtained on other surfaces $[14,15]$, the main band was attributed to the $\mathrm{BP}^{\bullet+}$ and the shoulder to $\mathrm{BP}^{\bullet-}$. The time

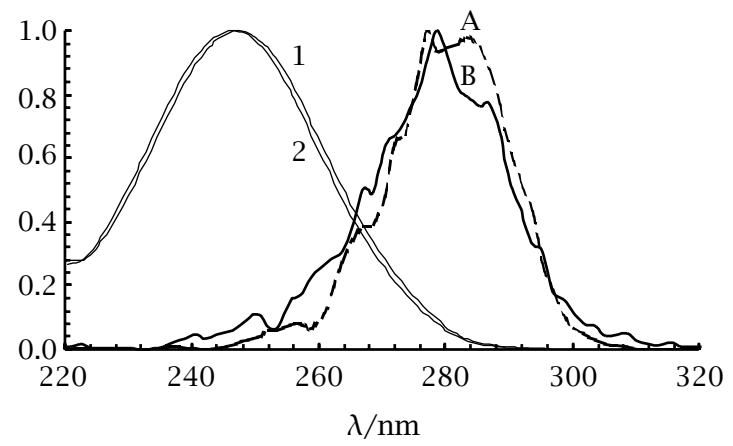

Figure 1. Normalized ground state absorption spectra of BP on cellulose (A) and silicalite (B) and in methanol (1) and iso-octane (2) solutions.

resolved luminescence studies on silicalite showed only a residual phosphorescence emission (data not shown). Therefore the contribution of the triplet state to the absorption between $300 \mathrm{~nm}$ and $400 \mathrm{~nm}$ is rather small. The absorption in this wavelength interval can be, in part, also attributed to the $\mathrm{BP}^{\bullet+}$ [14]. However, after $20 \mathrm{~ms}$ the $670 \mathrm{~nm}$ absorption of the $\mathrm{BP}^{\bullet+}$ practically vanishes and the band between 300 and $400 \mathrm{~nm}$ is blue shifted with maxima at $320 \mathrm{~nm}$ and at $360 \mathrm{~nm}$, suggesting the presence of other transients. This absorption can be due to the $\mathrm{OH}$ and/or to the $\mathrm{H}$ adducts of $\mathrm{BP}$ [33]. The detection of the triplet state only on cellulose was attributed to the well-known oxygen protection of this support to the entrapped probes [16-19], which is not observed in silicalite. This result suggests that the $\mathrm{BP}^{\bullet+}$ formation is favored in the presence of oxygen [34] and/or for molecules in closed contact with the silicalite surface.

3.3. Degradation products. Degradation studies show that BP is very stable in both supports. After $24 \mathrm{~h}$ irradiation $(254 \mathrm{~nm})$ the conversions were lower than $1 \%$. However by comparing the chromatograms of nonirradiated and irradiated samples, some photodegradation products were detected (see Figure 4).

On cellulose the three monohydroxybiphenyls were identified. The main degradation pathway suggested the formation of these compounds on $\gamma$-alumina, silicaalumina and clays involves the $\mathrm{BP}^{\bullet+}$ followed by $\mathrm{BPOH}^{\bullet}$ formation due to the reaction of the former with a water molecule $[11,12]$. The $\mathrm{BP}^{\bullet+}$ was not detected in significant amounts on this support. However, since the degradation rates were very low, this result does not exclude the proposed degradation pathway for the formation of hydroxybiphenyl compounds (see Scheme 1).

These compounds were expected in silicalite since the main transient in this support is the $\mathrm{BP}^{\bullet+}$. However the main identified degradation products in silicalite were benzaldehyde, acetophenone and benzyl alcohol (see Figure 4). Only traces of the hydroxybiphenyls were detected. The low formation of hydroxybiphenyls can be attributed to the lower water content of this 

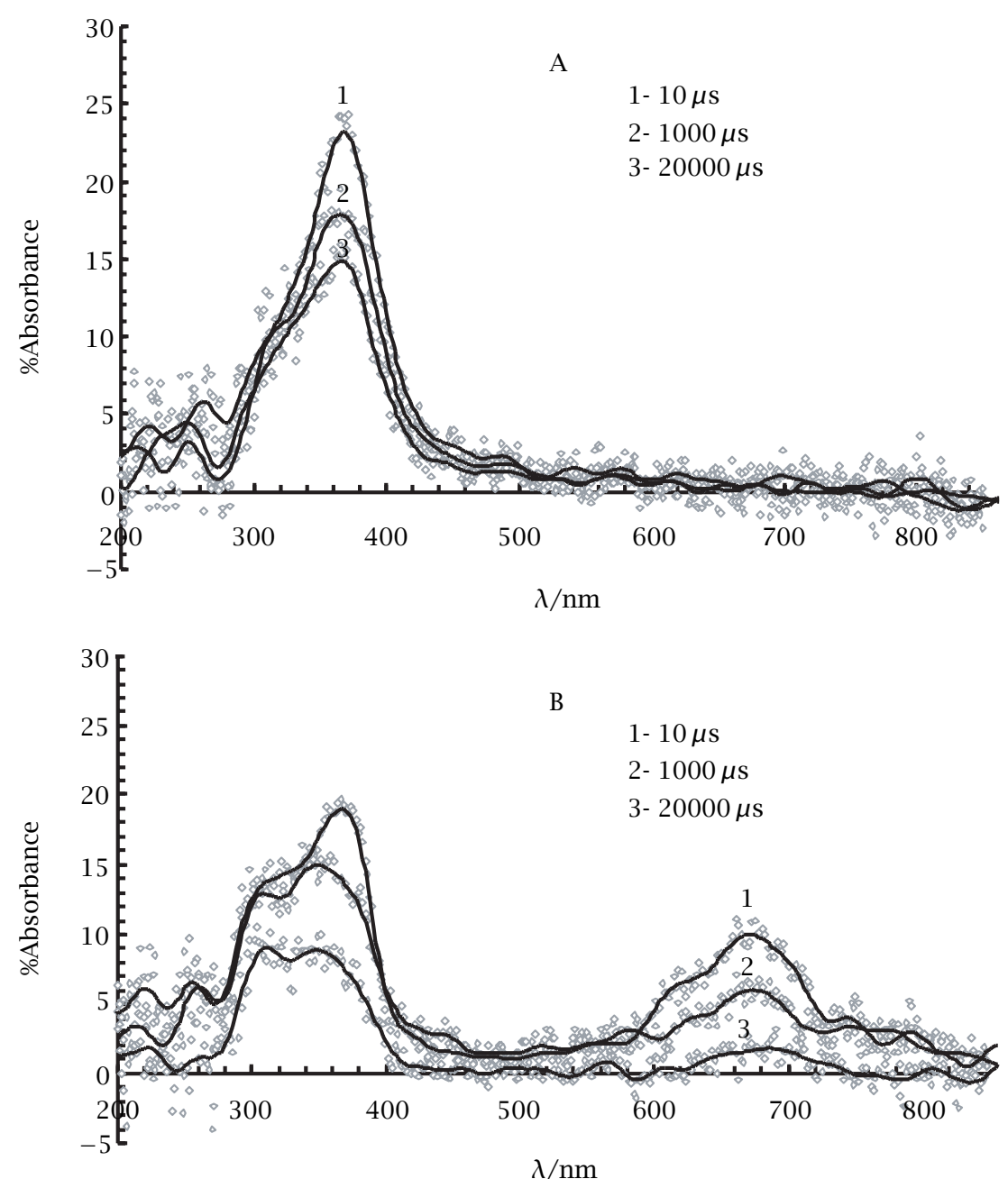

Figure 2. Transient absorption spectra of BP on cellulose (A) and silicalite (B) ( $\left.20 \mathrm{~mJ} / \mathrm{pulse}, 100 \mu \mathrm{mol} \mathrm{g}^{-1}\right)$.

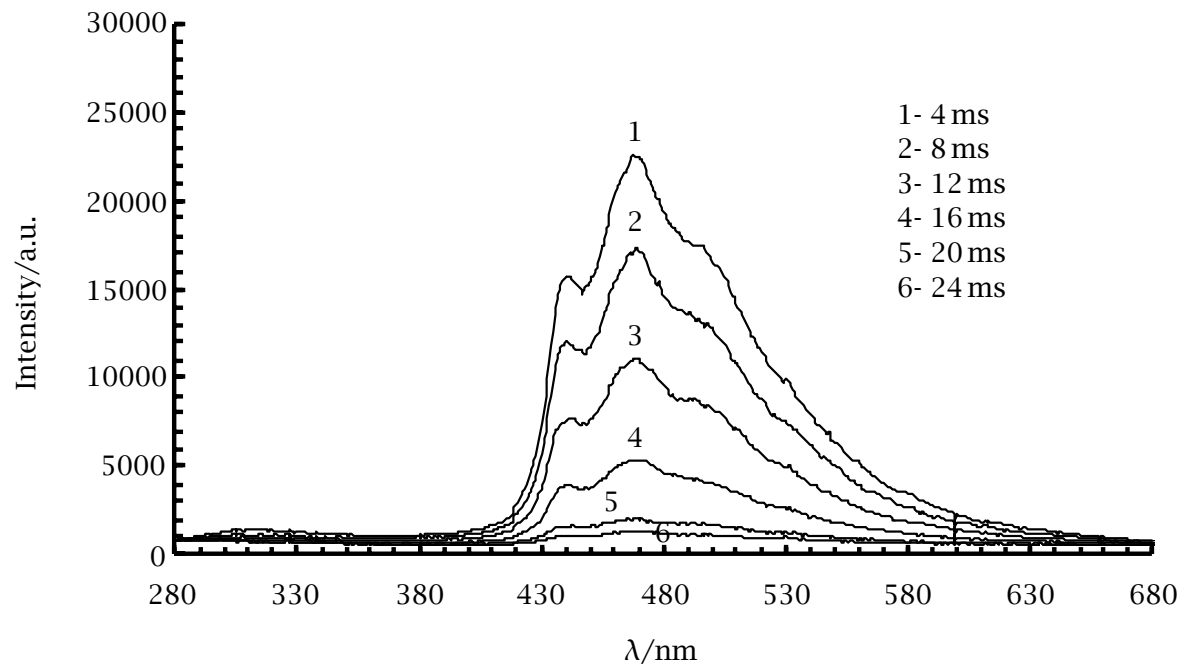

Figure 3. Time resolved luminescence spectra of BP on cellulose (20 mJ/pulse, $1000 \mu \mathrm{mol} \mathrm{g}{ }^{-1}$, gate with: $\left.20 \mathrm{~ms}\right)$. 

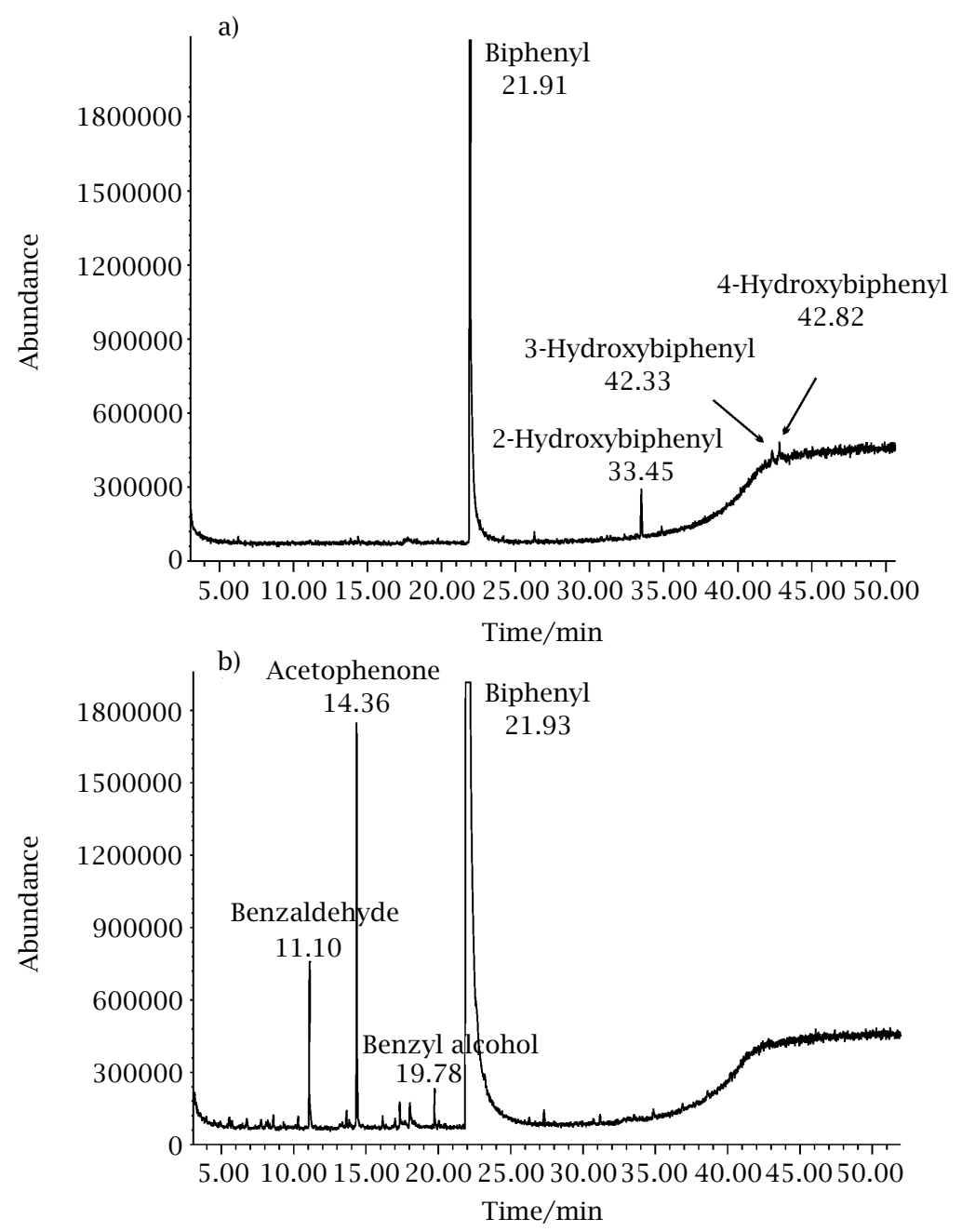

Figure 4. GC-MS chromatograms of the extracts of irradiated samples of BP on cellulose (a)) and silicalite (b)).

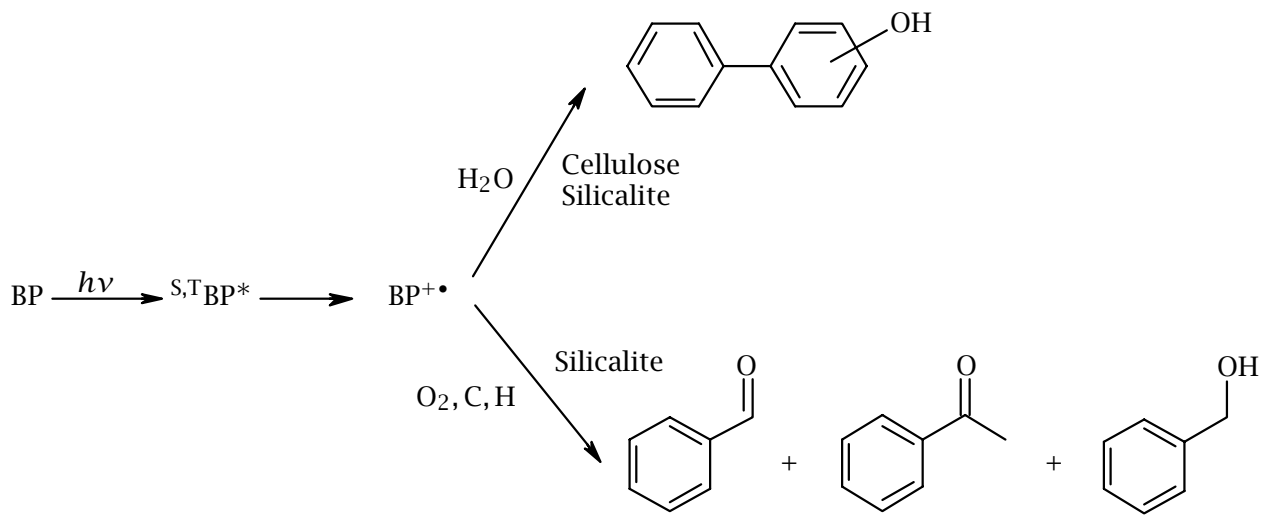

Scheme 1. Main photodegradation pathways of biphenyl adsorbed on cellulose and silicalite.

support, owing to its hydrophobic character. The formed degradation products must involve molecular oxygen [35], which, unlike the cellulose case, is present in silicalite. The degradation products also indicate the presence of a source of hydrogen and carbon (see Scheme 1). Initially we thought that the results can be due to the presence of solvent residues and/or solvent impurities such as linear alkanes which are able 
to enter into the silicalite channels during the sample preparation. However the same degradation products were detected on samples prepared by mechanical mixture. This source was attributed to impurities already present in silicalite, possibly resulting from the synthesis process. These impurities present in residual quantities allowed the formation of the detected products.

\section{CONCLUSIONS}

The adsorption of BP on cellulose and silicalite shifts the absorption spectra to the red region by inducing a near planar configuration of the ground state. Transient absorption and photoproduct results depend strongly on the support. Triplet-triplet absorption is the main transient on cellulose. The $\mathrm{BP}^{\bullet+}$ was only observed in significant amounts in silicalite. BP is relatively stable in both supports. After prolonged irradiations monohydroxybiphenyls were detected on cellulose, while on silicalite the main degradation products were benzaldehyde, acetophenone and benzyl alcohol.

\section{ACKNOWLEDGMENTS}

Post-doctor grant SFRH/BPD/5589/2001, supported by Fundação para a Ciência e a Tecnologia, is gratefully acknowledged.

\section{REFERENCES}

[1] J. L. Jacobson, S. W. Jacobson, and H. E. B. Humphrey, J. Pediatrics 116 (1990), 38.

[2] C. Baird, Environmental Chemistry, W. H. Freeman and Company, New York, 1999.

[3] L. O. Ruzo, M. J. Zabik, and R. D. Schuetz, J. Am. Chem. Soc. 96 (1974), 3809.

[4] N. J. Bunce, Y. Kumar, L. Ravanal, and S. Safe, J. Chem. Soc., Perkin Trans. 2 (1978), 880.

[5] J. Hawari, A. Demeter, and R. Samson, Environ. Sci. Technol. 26 (1992), 2022.

[6] Y. J. Lin, G. Gupta, and J. Baker, Chemosphere 31 (1995), 3323.

[7] S. K. Chaudhary, R. H. Mitchell, and P. R. West, Chemosphere 13 (1984), 1113.

[8] P. C. Zhang, R. J. Scrudato, J. J. Pagano, and R. N. Roberts, Chemosphere 26 (1993), 1213.

[9] J. Chiarenzelli, R. Scrudato, M. Wunderlich, D. Rafferty, K. Jensen, G. Oenga, R. Roberts, and J. Pagano, Chemosphere 31 (1995), 3259.

[10] I. W. Huang, C. S. Hong, and B. Bush, Chemosphere 32 (1996), 1869.

[11] Y. Mao and J. K. Thomas, J. Chem. Soc. Faraday Trans. 88 (1992), 3079.

[12] Y. Mao, G. Zhang, and J. K. Thomas, Langmuir 9 (1993), 1299.

[13] A. P. P. Cione, J. C. Scaiano, M. G. Neumann, and F. Gessner, J. Photochem. Photobiol. A: Chem. 118 (1998), 205.
[14] S. Hashimoto, T. Mutoh, H. Fukumura, and H. Masuhara, J. Chem. Soc. Faraday Trans. 92 (1996), 3653.

[15] I. Gener, G. Buntinx, and C. Brémard, Angew. Chem. Int. Ed. 38 (1999), 1819.

[16] E. M. Schulman and C. Walling, Science 178 (1972), 53.

[17] L. F. Vieira Ferreira, M. R. Freixo, A. R. Garcia, and F. Wilkinson, J. Chem. Soc. Faraday Trans. 88 (1992), 15.

[18] L. F. Vieira Ferreira, A. S. Oliveira, and J. C. NettoFerreira, in Fluorescence Mycroscopy and Fluorescence Probes 3, (A. Kotyk, Ed.), Espero Publishing, Prague, 1999, p. 199.

[19] L. F. Vieira Ferreira, M. J. Lemos, M. J. Reis, and A. M. B. do Rego, Langmuir 16 (2000), 5673.

[20] J. Koistinen, Chemosphere 24 (1992), 559.

[21] N. T. K. Oanh, B. E. Bengtsson, L. B. Reutergardh, D. T. Hoa, P. A. Bergqvist, D. Broman, and Y. Zebuhr, Arch. Environ. Contam. Toxicol. 37 (1999), 303.

[22] A. M. Botelho do Rego and L. F. Vieira Ferreira, in Handbook of Surfaces and Interfaces of Materials, (H. S. Nalwa, Ed.), vol. 2, Academic Press, chap. 7, p. 275.

[23] F. Wilkinson and G. P. Kelly, in Photochemistry on Solid Surfaces, (M. Anpo and T. Matsuara Eds.), Elsevier, Amsterdam, 1989, p. 31.

[24] L. F. Vieira Ferreira, J. C. Netto-Ferreira, I. V. Khmelinskii, A. R. Garcia, and S. M. B. Costa, Langmuir 11 (1995), 231.

[25] J. P. Da Silva, A. M. Da Silva, and I. V. Khmelinskii, Chemosphere 45 (2001), 875.

[26] J. P. Da Silva, A. M. Da Silva, I. V. Khmelinskii, J. M. G. Martinho, and L. F. Vieira Fereira, J. Photochem. Photobiol. A: Chem. 142 (2001), 31.

[27] J. P. Da Silva, L. F. Vieira Ferreira, and A. M. Da Silva, J. Photochem. Photobiol. A: Chem. 154 (2003), 293.

[28] J. P. Da Silva, L. F. Vieira Ferreira, A. M. Da Silva, and A. S. Oliveira, J Photochem. Photobiol. A: Chem. 151 (2002), 157.

[29] J. P. Da Silva, L. F. Vieira Ferreira, A. M. Da Silva, and A. S. Oliveira, Env. Sci. Technol. 37 (2003), 4798.

[30] L. F. Vieira Ferreira, I. Ferreira Machado, A. S. Oliveira, M. R. Vieira Ferreira, J. P. Da Silva, and J. C. Moreira, J. Phys. Chem. B 106 (2002), 12584.

[31] L. F. Vieira Ferreira, M. R. Vieira Ferreira, J. P. Da Silva, I. Ferreira Machado, A. S. Oliveira, and J. V. Prata, Photochem. Photobiol. Sci. 2 (2003), 1002.

[32] K. R. Naqvi, J. Donatsch, and U. P. Wild, Chem. Phys. Lett. 34 (1975), 285.

[33] K. Sehested and E. J. Hart, J. Phys. Chem. 79 (1975), 1639.

[34] H. Garcia and H. D. Roth, Chem. Reviews 102 (2002), 3947.

[35] T. Tamai, K. Mizuno, I. Hashida, and Y. Otsuji, Photochem. Photobiol. 54 (1991), 23. 


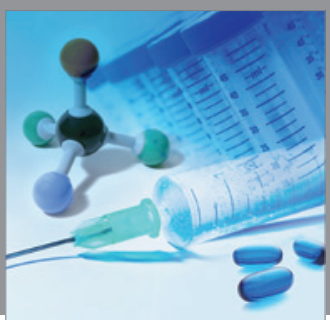

International Journal of

Medicinal Chemistry

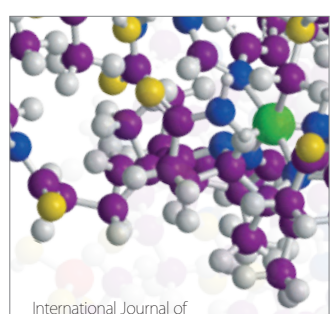

Carbohydrate Chemistry

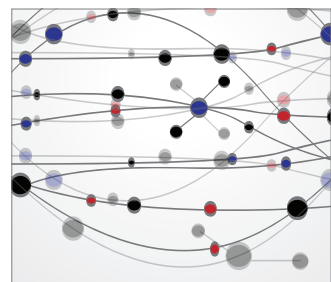

The Scientific World Journal
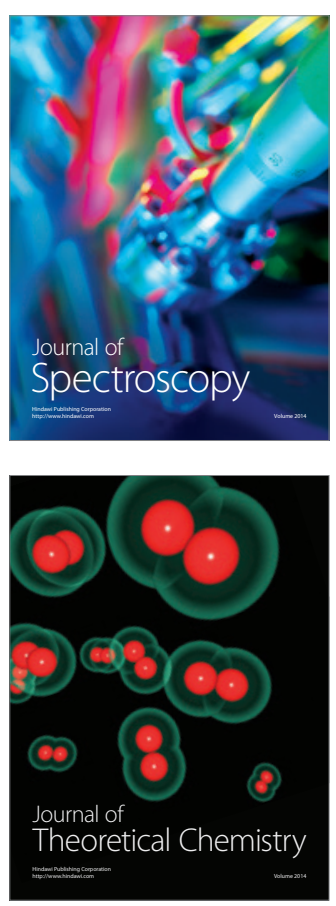
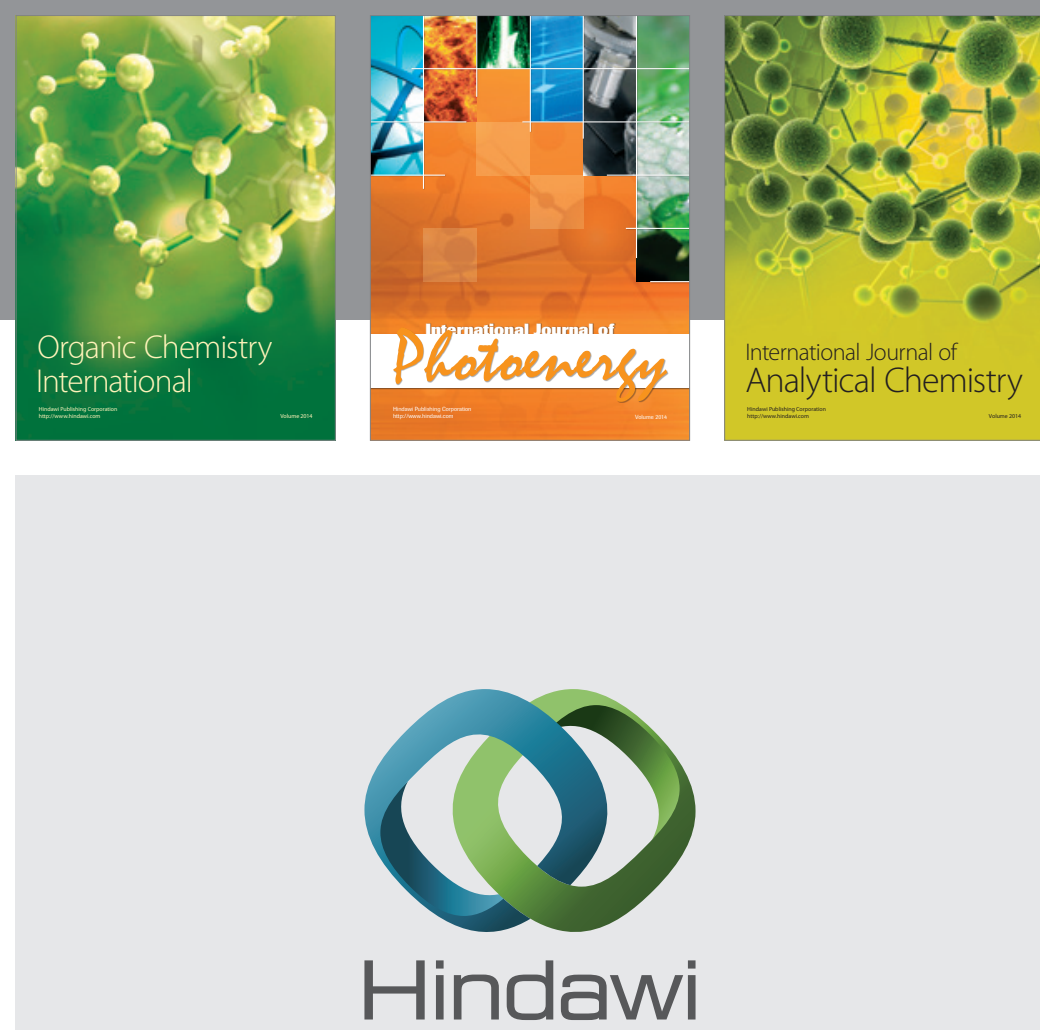

Submit your manuscripts at

http://www.hindawi.com
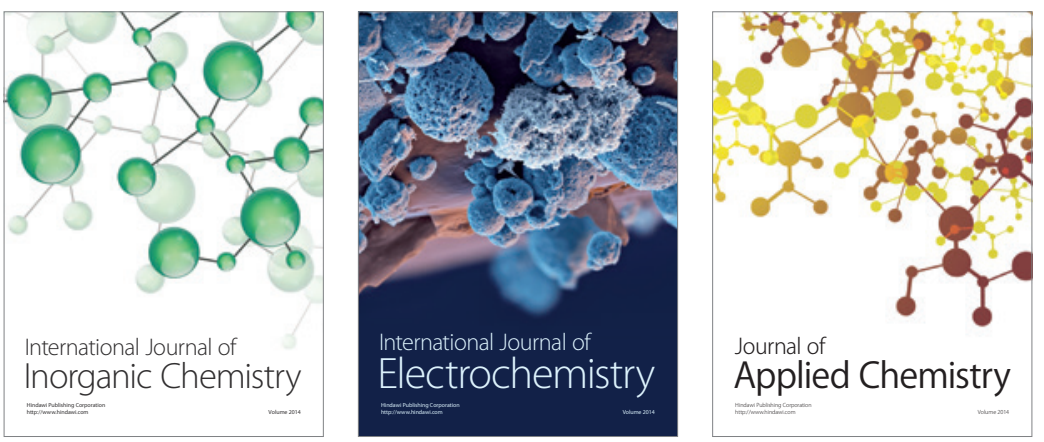

Journal of

Applied Chemistry
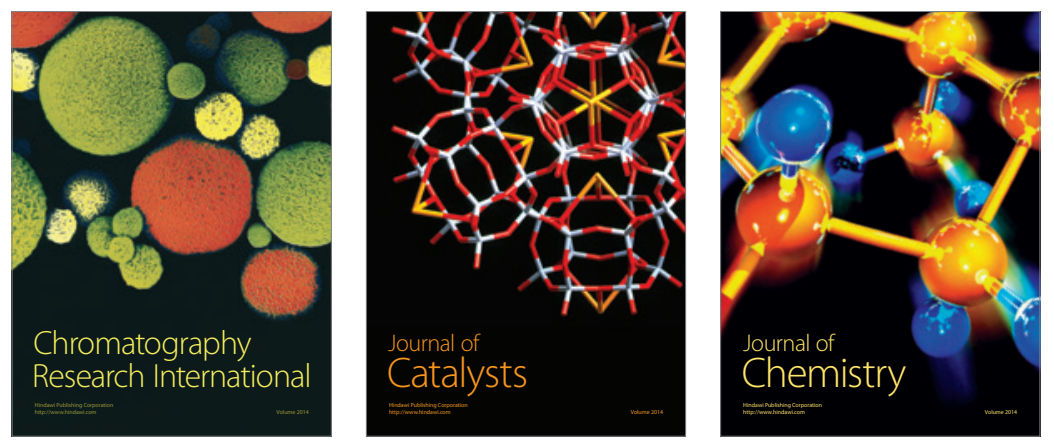
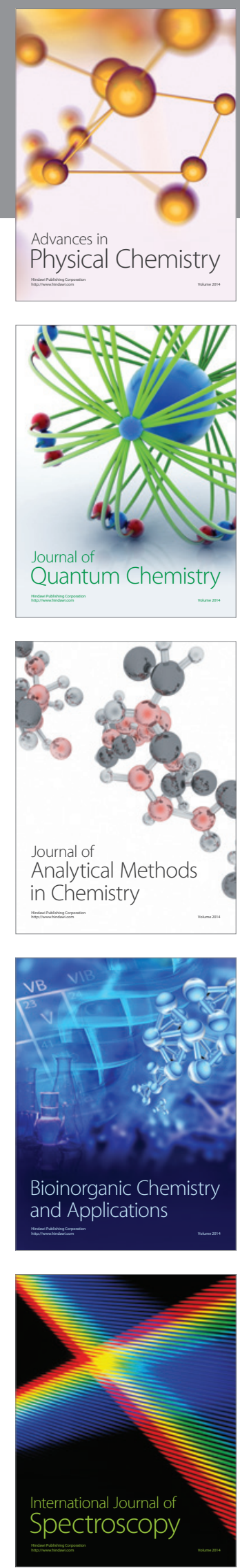